\title{
Ultrasonic Studies on the Molecular Interactions of Uranyl Soaps in Benzene-dimethylsulphoxide Mixture
}

\author{
Anubhuti Jain* and Sanjay K. Upadhyaya \\ Department of Chemistry, S.S.L. Jain P.G. College, Vidisha,464001,M.P., India
}

Received 3 July 3013; accepted 31 August 2013

\begin{abstract}
The ultrasonic measurements of solutions of uranyl caprylate and laurate in a mixture of 50/50 benzene-dimethylsulphoxide (V/V) have been used to determine the critical micellar concentration, ultrasonic velocity and various acoustic parameters at different temperatures. The results confirm that there is a significant interaction between uranyl soaps and the mixed organic solvent molecules. The values of critical micellar concentration of uranyl caprylate and laurate are in good agreement with those obtained from conductivity measurements.
\end{abstract}

Keywords: ultrasonic velocity, uranyl caprylate, uranyl laurate, acoustic parameters, critical micellar concentration.

\section{Introduction}

Metallic soaps are widely used in several domains such as detergency, lubricants, metal working, industrial air cleaning, chemical catalysis and cosmetology, etc. The properties and therefore applications of these soaps depend on the length of the fatty acid chain and on the associated metal ion, their physical state, stability, chemical reactivity and solubility in polar and non-polar solvents.

Lanthanide metal soaps were synthesized for the first time by Misra et al. [1-2] in the early $60_{\mathrm{s}}$. These soaps are being used as polymer stabilizers, catalysts, optical polymer fibres [3-6]. Surprisingly less attention has been paid on the physicochemical properties of rare-earth metal soaps.

The present work deals with the ultrasonic velocity measurements of uranyl caprylate and laurate in a mixture of 50\% benzene and 50\% DMSO (V/V) because these soaps possess solubility in this solvent mixture. This work has

\footnotetext{
* Corresponding author. E-mail address: anubhutijainj@gmail.com
} 
been initiated to calculate various allied parameters related to the acoustical properties of uranyl soaps.

\section{Experimental}

Merck/BDH reagent grade chemicals were used. Uranyl soaps were prepared by the direct metathesis of corresponding potassium soaps with uranyl acetate at 50$60{ }^{\circ} \mathrm{C}$ under vigorous stirring. The precipitated soaps were digested, filtered and washed with doubly distilled water and acetone. After initial drying in an air oven at $50-60{ }^{\circ} \mathrm{C}$, final drying was carried out under reduced pressure. The purity of these soaps was checked by elemental analysis and the results were found to be in good agreement with theoretically calculated values.

Ultrasonic measurements were carried out with a multifrequency ultrasonic interferometer (M-83, Mittal Enterprises, New Delhi) at 25, 30, 35, and $40{ }^{\circ} \mathrm{C}$ at $1 \mathrm{MHz}$ frequency. Water was maintained at the desired temperature and controlled to $\pm 0.5{ }^{\circ} \mathrm{C}$ by a thermostat passed through a jacket of cell before the measurements were actually made. The velocities measured at different temperatures have an uncertainty of $\pm 0.5 \mathrm{~ms}^{-1}$. The densities of the solutions were determined at different temperatures with RD bottles calibrated with pure benzene.

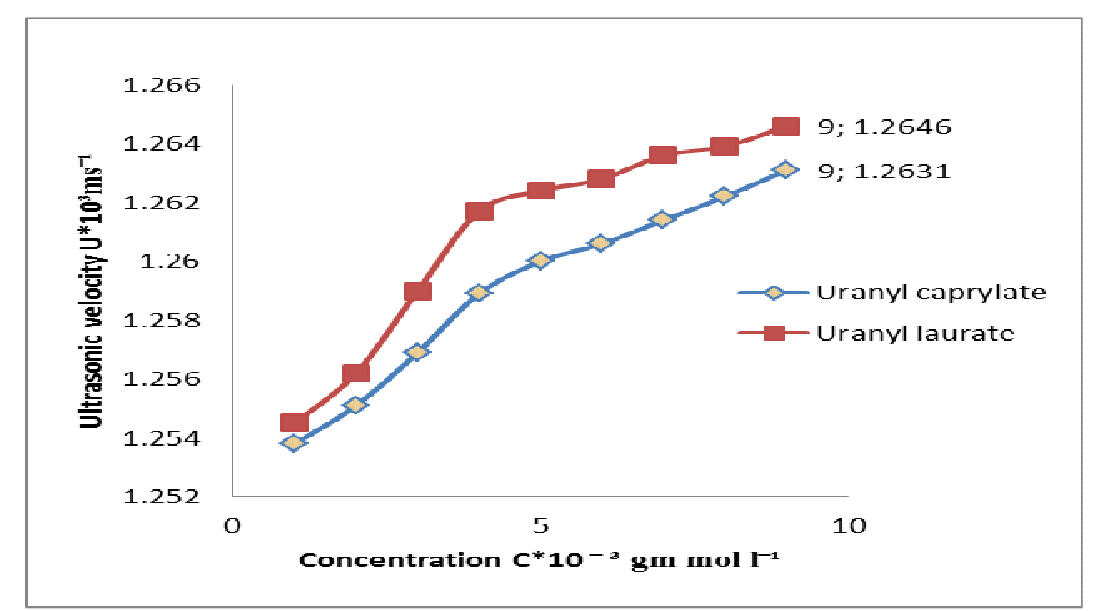

Figure 1. Ultrasonic velocity vs. concentration plots of uranyl soaps in $50 \%$ benzene and $50 \%$ dimethylsulphoxide mixture.

\section{Results and discussion}

The results indicate that ultrasonic velocity and density of uranyl soaps in 50/50 benzene-dimethylsulphoxide increase with increasing soap concentration and chain-length. The increase in velocity is due to the association between the uranyl soaps and mixed organic solvent molecules. The variation is not much appreciable at higher concentration when compared to lower concentrations. The variation in ultrasonic velocity $\mathrm{U}$ with soap concentration $\mathrm{C}$ for dilute solution is given by the following relation.

$$
U=U_{0}+G C
$$


where $\mathrm{U}_{0}$ is the ultrasonic velocity of the solvent and $\mathrm{G}$ is the Garnsey's constant [7]. The plots of ultrasonic velocity vs. concentration (Fig. 1) are extrapolated to zero soap concentration, to obtain values of $\mathrm{U}_{0}$ which is in good agreement with the experimental velocity, indicating that the soap molecules do not aggregate up to an appreciable extent below the CMC.

The plots of ultrasonic velocity $U$ versus soap concentration $C$ for uranyl soap are also characterized by an intersection of two straight lines at a definite soap concentration, which corresponds to the CMC. The values of CMC of uranyl caprylate and laurate in the mixture of $50 \%$ benzene and $50 \%$ DMSO increase with increasing temperature. The process of micellization was assumed to occur when the energy released as a result of aggregation of hydrocarbon chain of the monomers was sufficient to overcome and to balance the decrease in entropy accompanying aggregation. Since the kinetic energy of the monomer was higher at higher temperature, hence CMC will also be higher. The uranyl soaps form micelles at a particular concentration because of the balance between the attractive hydrophobic interaction of the long chain hydrocarbon tails and repulsive forces between the ionic head groups. The CMC decreases whereas Garnsey's constant $(\mathrm{G})$, determined from the slope of the plots of U vs. C, increases (Table 1) with increasing chain-length of the soap molecule.

Table 1. Values of the critical micellar concentration and Garnsey's constant of uranyl caprylate and laurate in $50 \%$ benzene and $50 \%$ dimethylsulphoxide mixtures (V/V) at different temperatures.

\begin{tabular}{|c|c|c|c|c|c|c|c|c|c|c|c|c|c|c|c|c|}
\hline $\begin{array}{c}\text { Name of } \\
\text { soaps }\end{array}$ & \multicolumn{4}{|c|}{$\begin{array}{c}\mathrm{CMC}^{*} 10^{3} \\
\text { (gm Mole/Lit.) }\end{array}$} & \multicolumn{4}{|c|}{$\begin{array}{c}\text { Garnsey's } \\
\text { constant } G^{*} 10^{3}\end{array}$} & \multicolumn{4}{|c|}{$\mathrm{A}^{*} 10^{10}$} & \multicolumn{4}{|c|}{$B * 10^{10}$} \\
\hline $\mathrm{T}\left({ }^{\circ} \mathrm{C}\right)$ & 25 & 30 & 35 & 40 & 25 & 30 & 35 & 40 & 25 & 30 & 35 & 40 & 25 & 30 & 35 & 40 \\
\hline $\begin{array}{l}\text { Uranyl } \\
\text { caprylate }\end{array}$ & 4.75 & 5.1 & 5.6 & 5.8 & 3.0 & 1.8 & 1.6 & 1.4 & -1.7 & -0.2 & 0.8 & 2.5 & -2.36 & -3.56 & -6.13 & -7.79 \\
\hline $\begin{array}{l}\text { Uranyl } \\
\text { laurate }\end{array}$ & 4.00 & 4.25 & 4.75 & 5.0 & 2.8 & 2.4 & 2.2 & 2 & -2.0 & -0.5 & 0.5 & 1.5 & -2.77 & -5.5 & -6.27 & -7.92 \\
\hline
\end{tabular}

The nature of adiabatic compressibility, $\beta$ and molar compressibility, $\mathrm{W}$, have been calculated by the following relationships:

$\beta=\rho^{-1} \cdot U^{-2}$

$W=\left(\frac{\bar{M}}{\rho}\right)(\beta)^{-\frac{1}{7}}$

The behaviour of adiabatic compressibility for uranyl caprylate and laurate soap solutions is reverse to that of ultrasonic velocity. The decrease in adiabatic compressibility with increasing concentration is attributed to the fact that in dilute solutions, the ions are furnished by the ionization of uranyl soap $\left(\mathrm{UO}_{2}{ }^{++}\right.$; $\mathrm{RCOO}^{-}$) . These ions are surrounded by a layer of mixed organic solvent molecules firmly bound and oriented towards the ions. The orientation of solvent molecules around the ions is attributed to the influence of electrostatic field of 
the ions. Thus, the internal pressure increases, lowering the compressibility of the solutions, i.e., the solutions become harder to compress [8].

The adiabatic compressibility of the soap solutions is found to obey Bachem's relationship.

$\beta=\beta_{0}+A C-B C^{3 / 2}$

The plots of adiabatic compressibility $\beta$ against soap concentration $\mathrm{C}$ also show a break at a definite concentration which corresponds to the $\mathrm{CMC}$, and these plots are extrapolated to zero soap concentration to give a value of $\beta_{0}$.

The plots of $\left[\beta-\beta_{0} / C\right]$ against $\sqrt{ } \mathrm{C}$ show a break at the CMC. The values of constants $\mathrm{A}$ and $\mathrm{B}$ obtained from the intercept and the slope of the plots of $[\beta$ $\left.\beta_{0} / \mathrm{C}\right]$ vs. $\sqrt{ } \mathrm{C}$ for uranyl soaps are mentioned in Table 1.

The molar compressibility, W, of uranyl soaps increases above CMC with increasing soap concentration and chain-length of the soap molecules.

The apparent molar volume, $\phi_{\mathrm{v}}$, of these soaps has been calculated by using the equation:

$\phi_{v}=\frac{M}{\rho_{0}}-\frac{\left(\rho-\rho_{0}\right) \times 10^{3}}{C \rho_{0}}$

The apparent molar volume, $\phi_{\mathrm{v}}$, decreases rapidly at first, then slowly, and finally increases with increasing the concentration of soap (Table 2). These changes in apparent molar volume is governed by various factors such as solvation of amphiphilic solutes, nature of ionic head group, length of non-polar part of solute and others. The values of partial molar volume, $\phi^{\circ}{ }_{\mathrm{v}}$, and experimental limiting slope, $S_{\mathrm{V}}$, for the solutions were evaluated from the intercept and the slope of the linear plots of $\phi_{\mathrm{v}} \mathrm{vs}$. $\sqrt{\mathrm{C}}$ below $\mathrm{CMC}$.

The apparent molar volume, $\phi_{\mathrm{v}}$, is related to the molar concentration of the soap by the Masson's equation given below.

$$
\phi_{v}=\phi_{v}^{0}+S_{v} c^{-1 / 2}
$$

The values for $\phi^{\circ}$ and $S_{V}$ (Table 3) are measures of ion-solvent and ion-ion interactions, respectively. $\phi^{\circ}{ }_{\mathrm{v}}$ values for these soaps increase with increasing temperature, however, $\mathrm{S}_{\mathrm{V}}$ decreases with increasing temperature.

The partial molar expansibility, $\mathrm{E}^{\circ}=\mathrm{d} \phi^{\circ}{ }_{\mathrm{v}} / \mathrm{dT}$, increases with increasing temperature; this may be due either to the decrease in electrostriction or to the loosening of solvent structure at higher temperature.

The intermolecular free length in a liquid system is a measure of molecular association. The intermolecular free length, $\left(\mathrm{L}_{\mathrm{f}}\right)$, and the specific acoustic impedance, $\mathrm{Z}$, of uranyl soaps in a mixture of 50/50 benzene-dimethylsulphoxide have been evaluated by using the following relationships

$L_{f}=K \sqrt{B}$

$Z=\rho U$ 
Table 2. Ultrasonic velocity and allied parameters of uranyl caprylate and laurate in $50 \%$ benzene and $50 \%$ dimethylsulphoxide mixture at $25 \pm 0.05^{\circ} \mathrm{C}$.

\begin{tabular}{|c|c|c|c|c|c|c|c|}
\hline $\begin{array}{l}\text { Concen- } \\
\text { tration } \\
\mathrm{C} \times 10^{3}\end{array}$ & $\begin{array}{c}\text { Density } \\
\rho\end{array}$ & $\begin{array}{l}\text { Ultrasonic } \\
\text { velocity } \\
\mathrm{U} \times 10^{-3}\end{array}$ & $\begin{array}{c}\text { Specific } \\
\text { acoustic } \\
\text { impedance } \\
\mathrm{Z} \times 10^{-5}\end{array}$ & $\begin{array}{c}\text { Inter-molecular } \\
\text { free-length } \\
\mathrm{L}_{\mathrm{f}}\end{array}$ & $\begin{array}{c}\text { Molar } \\
\text { compressibility } \\
\mathrm{W}^{*} 10^{4}\end{array}$ & $\begin{array}{c}\text { Adiabatic } \\
\text { compressi- } \\
\text { bility } \\
\beta \times 10^{10}\end{array}$ & $\begin{array}{c}\text { Apparent } \\
\text { molar } \\
\text { volume } \\
\phi_{\mathrm{V}}\end{array}$ \\
\hline $\mathrm{gmol} \mathrm{L}^{-1}$ & $\mathrm{kgm}^{-3}$ & $\mathrm{~m} / \mathrm{s}$ & $\mathrm{kgm}^{-2} \mathrm{~s}^{-1}$ & $\mathrm{~A}^{0}$ & $\left(\mathrm{~m}^{3} / \mathrm{mol} .\left(\mathrm{N} / \mathrm{m}^{2}\right)^{1 / 7}\right)$ & $\mathrm{m}^{2} \mathrm{~N}^{-1}$ & $\mathrm{mkg}^{-1} \mathrm{~s}^{2}$ \\
\hline \multicolumn{8}{|c|}{ Uranyl caprylate } \\
\hline 1.0 & 990.8 & 1.2538 & 12.42 & 0.5067 & 49.11 & 6.420 & -201.3 \\
\hline 2.0 & 991.1 & 1.2551 & 12.44 & 0.5061 & 49.17 & 6.405 & -251.8 \\
\hline 3.0 & 991.2 & 1.2569 & 12.46 & 0.5054 & 49.25 & 6.386 & -261.3 \\
\hline 4.0 & 991.5 & 1.2589 & 12.48 & 0.5045 & 49.34 & 6.363 & -226.5 \\
\hline 5.0 & 991.6 & 1.2600 & 12.49 & 0.5041 & 49.39 & 6.352 & -201.3 \\
\hline 6.0 & 991.7 & 1.2606 & 12.50 & 0.5038 & 49.44 & 6.345 & -184.5 \\
\hline 7.0 & 991.8 & 1.2614 & 12.51 & 0.5034 & 49.49 & 6.336 & -172.5 \\
\hline 8.0 & 991.9 & 1.2622 & 12.52 & 0.5031 & 49.55 & 6.328 & -163.5 \\
\hline 9.0 & 992.0 & 1.2631 & 12.53 & 0.5027 & 49.60 & 6.318 & -156.5 \\
\hline \multicolumn{8}{|c|}{ Uranyl laurate } \\
\hline 1.0 & 990.9 & 1.2539 & 12.42 & 0.5067 & 49.12 & 6.418 & -302.1 \\
\hline 2.0 & 991.2 & 1.2562 & 12.45 & 0.5057 & 49.21 & 6.393 & -312.2 \\
\hline 3.0 & 991.4 & 1.2590 & 12.48 & 0.5045 & 49.33 & 6.363 & -320.6 \\
\hline 4.0 & 991.7 & 1.2617 & 12.51 & 0.5033 & 49.45 & 6.334 & -276.9 \\
\hline 5.0 & 991.8 & 1.2624 & 12.52 & 0.5030 & 49.50 & 6.326 & -241.6 \\
\hline 6.0 & 991.9 & 1.2628 & 12.53 & 0.5029 & 49.52 & 6.322 & -218.0 \\
\hline 7.0 & 992.0 & 1.2636 & 12.53 & 0.5025 & 49.58 & 6.313 & -201.2 \\
\hline 8.0 & 992.1 & 1.2639 & 12.54 & 0.5024 & 49.64 & 6.309 & -188.6 \\
\hline 9.0 & 992.2 & 1.2646 & 12.55 & 0.5021 & 49.69 & 6.302 & -178.7 \\
\hline
\end{tabular}

Table 3. $\phi_{\mathrm{v}}^{\circ}, \mathrm{S}_{\mathrm{v}}$ and $\mathrm{E}^{\circ}=\left(\mathrm{d} \phi^{\circ}{ }_{\mathrm{v}} / \mathrm{dt}\right)$ of uranyl soaps in $50 \%$ benzene and $50 \%$ dimethylsulphoxide mixture at different temperatures.

\begin{tabular}{|c|lcc|lcc|}
\hline Temp $\left({ }^{\circ} \mathbf{C}\right)$ & \multicolumn{3}{|c|}{ Uranyl.caprylate } & \multicolumn{3}{c|}{ Uranyl.laurate } \\
\hline & $\mathbf{- \phi}_{\mathbf{v}}{ }_{\mathbf{v}}$ & $\mathbf{- S}_{\mathbf{v}}$ & $\mathbf{- E}^{\circ}$ & $\mathbf{- \phi}^{\circ}{ }_{\mathbf{v}}$ & $\mathbf{- S}_{\mathbf{v}}$ & $\mathbf{- E}^{\circ}$ \\
25 & 160 & 13.7 & 0.53 & 250 & 22.4 & 0.83 \\
30 & 100 & 24.7 & 0.33 & 125 & 36.3 & 0.41 \\
35 & 80 & 33.6 & 0.25 & 110 & 39.4 & 0.35 \\
40 & 25 & 38.5 & 0.07 & 80 & 40.5 & 0.25 \\
\hline
\end{tabular}

The intermolecular free length, $\left(\mathrm{L}_{\mathrm{f}}\right)$, decreases, whereas the specific acoustic impedance, $\mathrm{Z}$, increases with increasing soap concentration. Specific acoustic impedance, $\mathrm{Z}$, in a liquid system can be used to assess the molecular interaction between the components [9]. This indicates that there is a significant interaction between uranyl soaps and non-aqueous solvent molecules [10-12] due to which the structural arrangement is affected. The increase in the values of $\mathrm{Z}$ with increasing concentration (Table 2) may be due to the lyophobic interaction between uranyl soaps and the solvent molecules, which increases the intermolecular distance, opening a relatively wide gap between the molecules and becoming the main cause of impedance in the propagation of ultrasound waves. The plots of intermolecular free length $\mathrm{L}_{\mathrm{f}}$ and specific acoustic impedance $\mathrm{Z}$ against concentration show a break at the CMC. These results are in agreement with the results of other workers [13]. This again confirms the fact that the soap molecules do not aggregate to an appreciable extent below the $\mathrm{CMC}$, whereas there is a marked change in aggregation at the CMC. 
The relative association, $R_{A}$ [14] and solvation number, $S_{n}$ [15] of uranyl soaps determined by the following relationships, are shown in Table 4.

$\mathrm{R}_{\mathrm{A}}=\left(\frac{\rho}{\rho_{0}}\right)\left(\frac{\mathrm{U}_{0}}{\mathrm{U}}\right)^{1 / 3}$

$s_{n}=\frac{n_{0}}{n}\left[\frac{1-\bar{V} \beta}{n_{0} \beta_{0} \bar{V}_{0}}\right]$

Here $U_{0}, U, \rho_{0}, \rho, n_{0}, n, \beta_{0}, \bar{\beta}, V_{0}$ and $V$ are the ultrasonic velocity, density, number of moles, adiabatic compressibility and molar volume of solvent and solutions, respectively. The values of relative association, $\mathrm{R}_{\mathrm{A}}$, decrease with increasing soap concentration and chain-length of the uranyl soap molecules. The solvation number, $S_{n}$, decreases with increasing the concentration and chainlength of the soap molecules. The values of $S_{n}$ correspond to the number of solvent molecules in the primary solvation sheath of ions. The positive value of solvation number indicates appreciable solvation of ions.

Table 4. Acoustical parameters of uranyl caprylate and laurate in $50 \%$ benzene and $50 \%$ dimethylsulphoxide mixture at $25 \pm 0.05^{\circ} \mathrm{C}$.

\begin{tabular}{|c|c|c|c|c|c|c|c|c|}
\hline $\begin{array}{c}\text { Concen- } \\
\text { tration } \\
\mathrm{C} \times 10^{3}\end{array}$ & $\begin{array}{c}\text { Apparent } \\
\text { molar } \\
\text { compressi- } \\
\text { bility } \\
-\phi_{\mathrm{K}} \times 10^{8}\end{array}$ & $\begin{array}{c}\text { Relaxation } \\
\text { strength } \\
\text { r }\end{array}$ & $\begin{array}{c}\text { Relative } \\
\text { association } \\
\mathrm{R}_{\mathrm{A}}\end{array}$ & $\begin{array}{c}\text { Rao's } \\
\text { number } \\
\text { Rn×10 }\end{array}$ & $\begin{array}{c}\text { Solvation } \\
\text { number } \\
\text { Sn }\end{array}$ & $\begin{array}{c}\text { Viscosity } \\
\eta\end{array}$ & $\begin{array}{c}\text { Internal } \\
\text { pressure } \\
\pi^{*} 10^{12}\end{array}$ & $\begin{array}{c}\text { Available } \\
\text { volume } \\
\left(\mathrm{V}_{\mathrm{a}} \times 10^{2}\right)\end{array}$ \\
\hline $\mathrm{gmol} \mathrm{l}^{-1}$ & $\begin{array}{l}\mathrm{m}^{5} \mathrm{~N}^{-1} \\
(\mathrm{kmol})^{-1}\end{array}$ & $\left(\mathrm{~ms}^{-1}\right)$ & & & & Centipoise & Pascal & $\left(\mathrm{m}^{-3}\right)$ \\
\hline \multicolumn{9}{|c|}{ Uranyl caprylate } \\
\hline 1.0 & 1.89 & 0.385 & 0.9996 & 849.7 & 270.1 & 0.780 & 3.80 & 1.705 \\
\hline 2.0 & 1.90 & 0.384 & 0.9996 & 850.1 & 136.2 & 0.787 & 3.82 & 1.698 \\
\hline 3.0 & 1.95 & 0.382 & 0.9992 & 850.9 & 91.8 & 0.796 & 3.85 & 1.690 \\
\hline 4.0 & 1.99 & 0.380 & 0.9990 & 851.5 & 69.7 & 0.805 & 3.87 & 1.681 \\
\hline 5.0 & 1.84 & 0.379 & 0.9988 & 852.0 & 56.1 & 0.812 & 3.88 & 1.676 \\
\hline 6.0 & 1.66 & 0.379 & 0.9987 & 852.5 & 46.9 & 0.814 & 3.89 & 1.674 \\
\hline 7.0 & 1.55 & 0.378 & 0.9986 & 853.0 & 40.4 & 0.816 & 3.96 & 1.670 \\
\hline 8.0 & 1.47 & 0.377 & 0.9985 & 853.5 & 35.5 & 0.820 & 4.35 & 1.667 \\
\hline 9.0 & 1.42 & 0.376 & 0.9984 & 854.0 & 31.7 & 0.822 & 4.95 & 1.663 \\
\hline \multicolumn{9}{|c|}{ Uranyl laurate } \\
\hline 1.0 & 2.13 & 0.384 & 0.9995 & 849.7 & 270.3 & 0.782 & 3.81 & 1.704 \\
\hline 2.0 & 2.43 & 0.383 & 0.9994 & 850.5 & 137.1 & 0.791 & 3.83 & 1.693 \\
\hline 3.0 & 2.65 & 0.380 & 0.9988 & 851.5 & 92.9 & 0.799 & 3.85 & 1.680 \\
\hline 4.0 & 2.76 & 0.378 & 0.9984 & 852.3 & 70.8 & 0.807 & 3.87 & 1.667 \\
\hline 5.0 & 2.38 & 0.377 & 0.9984 & 852.9 & 56.9 & 0.812 & 3.88 & 1.665 \\
\hline 6.0 & 2.07 & 0.377 & 0.9983 & 853.4 & 47.5 & 0.814 & 3.89 & 1.664 \\
\hline 7.0 & 1.91 & 0.376 & 0.9982 & 854.0 & 40.9 & 0.817 & 3.90 & 1.660 \\
\hline 8.0 & 1.72 & 0.375 & 0.9981 & 854.5 & 35.9 & 0.821 & 4.95 & 1.660 \\
\hline 9.0 & 1.62 & 0.374 & 0.9980 & 855.1 & 32.0 & 0.825 & 5.03 & 1.657 \\
\hline
\end{tabular}

Internal pressure, $\pi$ [16] and available volume, $\cdot V_{a}$ [17] of uranyl soaps were calculated by the following relationships and the results obtained are shown in Table 4. 
$\Pi=b R T\left[\frac{K \eta}{U}\right]^{1 / 2}\left[\rho^{2 / 3} \bar{M}^{7 / 6}\right]$

where $b$ stands for the cubic packing factor which is assumed to be 2 for all liquids and solutions, $\mathrm{K}$ is a temperature independent constant $\left(4.28^{*} 10^{9}\right), \mathrm{R}$ is the gas constant $\left(8.3143 \mathrm{JKmol}^{-1}\right), \mathrm{T}$ is the absolute temperature, $\mathrm{M}$ is the effective molecular weight of solution and $U$ is equivalent to $1600 \mathrm{~ms}^{-1}$.

Internal pressure, $(\pi)$ increases rapidly with the increase of concentration and chain-length.

The apparent molar compressibility, $\phi_{\mathrm{k}}$, and the available volume, Va, have been calculated by the following relationships:

$$
\begin{aligned}
& \phi_{k}=1000 \frac{\left(\beta \rho_{0}-\beta_{0} \rho\right)}{C_{\rho_{0}}}+\frac{\beta m}{\rho} \\
& V_{a}=\bar{V}\left(\frac{1-U}{U \alpha}\right)
\end{aligned}
$$

The negative value of the apparent molar compressibility, $\left(\phi_{\mathrm{k}}\right)$, in Table 4 , first increases linearly with concentration in the pre-micellization region, but decreases sharply in the post-micellization region, indicating poor compressibility at the higher soap concentrations. The available volume, $\mathrm{V}_{\mathrm{a}}$ decreases with increasing concentration and chain-length. The plots of $\mathrm{V}_{\mathrm{a}}$ vs. $\mathrm{C}$ are characterized by a break of the CMC. Rao's number, $\mathrm{R}_{\mathrm{n}}$ [18] and relaxation strength, $r$, were calculated by the following relationships, and the results obtained are mentioned in Table 4.

$$
\begin{aligned}
& R_{n}=\left(\frac{\bar{M}}{\rho}\right) U^{1 / 3} \\
& r=1-\left(\frac{U}{U_{\alpha}}\right)^{2}
\end{aligned}
$$

where $\mathrm{U}_{\alpha}$ is equivalent to $1600 \mathrm{~ms}^{-1}$.

It is observed that Rao's constant shows a regular, almost linear increase with concentration and increasing chain length of the soaps. The values of relaxation strength, $r$, of uranyl soaps decrease with increasing the concentration and chainlength of the uranyl soap molecules supporting soap-solvent interactions. The results of uranyl soaps are in agreement with the work reported earlier [19-22] by other workers.

\section{Conclusions}

The ultrasonic velocity throws light on evaluation of various acoustical parameters of uranyl caprylate and laurate in benzene-dimethylsulphoxide mixture. These results confirm that there is a significant interaction between uranyl soaps and solvent molecules in dilute solutions and the soap molecules do 
not aggregate appreciably below the $\mathrm{CMC}$. The values of $\mathrm{CMC}$ for uranyl soaps (caprylate and laurate) increase with increasing temperature.

\section{Acknowledgement}

The authors are grateful to Principal, S.S.L. Jain P.G. College, Vidisha for providing laboratory facilities.

\section{References}

1. Misra SN, Misra TN, Mehrotra RC. J Inorg Nucl Chem. 1963;25:195.

2. Misra SN, Misra TN, Mehrotra RC. J Inorg Nucl Chem. 1963;25:201.

3. Ducros P, J Less Common Met. 1985;111:37.

4. Sauvion GN, Bains MS, Gothi JS. Indian J Chem. 1969;7:514.

5. Zhang Q, Ming H, Zhai Y. Polymer Int. 1996;41:413.

6. Zhang Q, Ming H, Zhai Y. J Appl Polym Sci.1996;62:887 .

7. Garnsey R, Boe RJ, Mahoney R, et al. J Chem Phys. 1969;50:5222.

8. Prakash S, Ichhaporia FM, Pandey JD. J Phys Chem. 1964;58:3078.

9. Atkins PW. Physical chemistry. Oxford: Oxford University Press; 1994. $5^{\text {th }}$ ed, p. 781.

10. Prakash S, Prakash O. Acoustica. 1975;32:279.

11. Prakash S, Prasad N, Prakash O. J Chem Eng Data 1977;22:51.

12. Allam D, Lee W, J Chem Soc. 1969;6049.

13. Mehrotra KN, Tondon K. Monatsh Chemie. 1990;121:577.

14. Waissler A. J Chem Phys. 1947;15:210.

15. Shoemaker DP, Garland CW. Experiments in physical chemistry. New York: McGraw Hill; 1967.

16. Raju K, Rakkappan C. Asian J Chem. 2011;23:19.

17. Schaafts W. Z Phys A. 1939;114:110

18. Rao MR. Indian J Phys. 1940;14:109.

19. Gupta A, Upadhyaya SK. Cellulose Chem Technol. 2013;47:77.

20. Upadhyaya SK, Chaturvedi PK. J Ind Coun Chem. 2007;24:74.

21. Rawat MK, Sharma Y, Kumari S. Asian J Chem. 2008;20:1464.

22. Kishore K, Upadhyaya SK. Tenside Surf Det. 2011;47:189. 